\title{
Imaginario colectivo popular como constructo del Programa de Mejoramiento Integral de Barrios, en Bogotá
}

\author{
Popular collective imaginary as a construct of the Comprehensive Neighborhood \\ Improvement Program in Bogotá
}

\section{Alejandro Jesús Guerrero-Torrenegra}

Universidad del Valle, Cali (Colombia)

Facultad de Artes Integradas, Programa de Arquitectura

Departamento de Proyectos

Colectivo de Investigaciones Territorio, Construcción y Espacio (CITCE)

Guerrero-Torrenegra A. J. (2021). Imaginario colectivo popular como constructo del Programa de Mejoramiento Integral de Barrios, en Bogotá. Revista de Arquitectura (Bogotá), 23(2), 12-23. https://doi.org/10.14718/RevArq.2021.3011

\footnotetext{
Arquitecto, Universidad Autónoma del Caribe. Barranquilla (Colombia).

Doctor en Arquitectura, Universidad del Zulia. Maracaibo (República Bolivariana de Venezuela).

Magister en Gerencia de Proyectos de I+D, Universidad Rafael Belloso Chacín. Maracaibo (República Bolivariana de Venezuela). Profesor asistente, Universidad del Valle, e investigador con énfasis en Hábitat y Arquitectura.

https://scholar.google.com/citations?user=iDTh9sQAAAAJ\&hl=es (D) https://orcid.org/0000-0003-4691-0803

(a) alejandro.torrenegra@correounivalle.edu.co
}

\begin{abstract}
Resumen
Este artículo trata de develar la fragmentación ocasionada entre los Programas de Mejoramiento Integral de Barrios (PMIB) y el imaginario colectivo popular de los ocupantes de los asentamientos informales. El objetivo de esta investigación es interpretar la relación de los PMIB en Ciudad Bolívar, en Bogotá, D. C. (2012-20I5) con el imaginario colectivo popular de los habitantes de dicha localidad, como constructo socioespacial. La aproximación metodológica está conformada por procesos sistemáticos apoyados en un método que pretende mostrar una radiografía de la complejidad de lo real en relación con el fenómeno socioespacial, desde un enfoque mixto, mediante la aplicación de métodos (fenomenológico y hermenéutico), con la perspectiva del pensamiento complejo, para establecer la dialéctica entre lo espacial, lo social y el Estado. Finalmente, se confirma que los PMIB generan un detrimento de las dimensiones sociales y espaciales que componen las especificidades fundacionales e históricas del barrio.
\end{abstract}

Palabras clave: asentamiento humano; construcción de vivienda; espacio urbano; territorio ocupado; comunidad

\section{Abstract}

This article tries to unveil the fragmentation caused by the Programas de Mejoramiento Integral de Barrios (PMIB) [Comprehensive Neighborhood Improvement Programs (PMIB, for its Spanish acronym)] and the popular collective imaginary of the occupants of informal settlements. The objective of this research is to interpret the relationship of the PMIBs in Ciudad Bolivar, in Bogotá, D.C. (2012 - 2015), with the popular collective imaginary of the inhabitants of that locality, as a socio-spatial construct. The methodological approach is shaped by systematic processes supported by a method that aims to show an X-ray of the complexity of reality in relation to the socio-spatial phenomenon, from a mixed approach, through the application of methods (phenomenological and hermeneutic) with the perspective of complex thinking, to establish the dialectics between the spatial, the social and the State. Finally, it is confirmed that the PMIB generate a detriment of the social and spatial dimensions that make up the foundational and historical specificities of the neighborhood. Keywords: community; human settlement; housing construction; occupied territory; urban space 


\section{Introducción}

En este artículo se presentan los resultados de una investigación sobre la vinculación de las dimensiones sociales y físico-espaciales en el desarrollo de los PMIB en la ciudad de Bogotá, D. C. El punto de partida es entender que el imaginario colectivo popular es la memoria colectiva popular de sus habitantes, y el espacio físico es el lugar donde la vida se desarrolla; así mismo, que los PMIB son el instrumento para mejorar las condiciones de habitabilidad de los mencionados sectores a partir de sus necesidades.

Los sectores informales de la ciudad de Bogotá son mayoritarios y crecientes, y conocidos también como barrios o periferias informales. Se caracterizan por la segregación en lo económico, en lo social y en lo espacial; esto, debido a las grandes carencias en los servicios públicos, a la dificultad en el acceso a la vivienda formal y al déficit en las condiciones urbanas, todo lo cual produce la consolidación del modelo de ciudad difusa, que, al fragmentar territorialmente los sistemas productivos, genera una fractura en los sistemas y en las dinámicas urbanos.

La situación descrita es causada por la ausencia de mecanismos e instrumentos de planificación urbana durante la conformación y la consolidación de este tipo de asentamientos humanos. Según Hernández (2005),

Han construido y apropiado su hábitat, han desarollado y expresado sus sueños de un futuro a partir de una construcción colectiva explícita e implícita, de una visión comunitaria no siempre compartida pero presente, y a través de unos mecanismos de participación a veces brindados y otras muchas exigidos. (p. 49)

La respuesta brindada en políticas públicas a esta crisis urbana, a finales de la década de 1970, se dio en un escenario marcado por la intervención del Estado y de efervescencia social, dos corrientes que influyeron en la trazabilidad de las investigaciones urbanas sociales. Por una parte, la corriente liderada por Manuel Castells, la cual puso en el centro del debate los movimientos sociales urbanos que se esperaba que produjeran transformaciones en las políticas y en la planificación urbanas.

Por otra parte, está la corriente de los investigadores que se ampararon en la teoría del capitalismo monopolista del Estado, que esperaba generar una trasformación social a partir de un cambio político en el ámbito estatal.

Ambas corrientes expusieron el accionar del Estado y la economía como elementos clave para la organización de las grandes ciudades, pero sin correspondencia con las necesidades y los valores de todos los grupos sociales al mismo tiempo, sino con los dominantes como los grandes favorecidos por la política urbana.

En contraste con lo anterior, la población de escasos recursos o en situación de pobreza tie- ne limitaciones para acceder al suelo urbano y la vivienda propia, y así se convierte en un grupo dominado. Sus procesos de reproducción social se enmarcan dentro de la autoproducida, edificada por su propio usuario durante un periodo, mediante un proceso abierto y continuo, como se puede inferir en el siguiente testimonio:

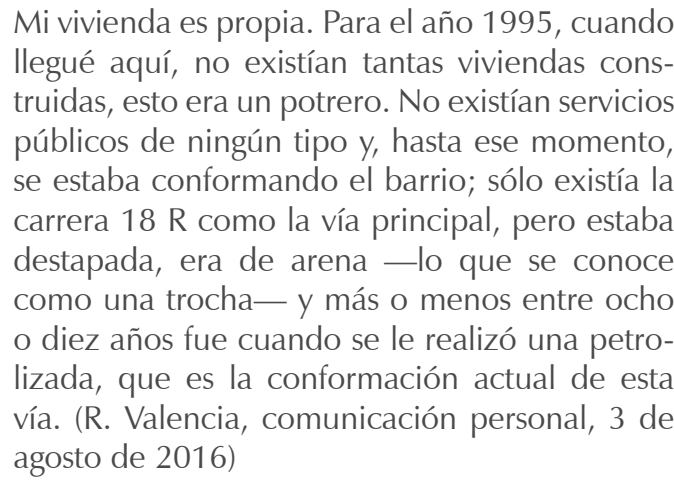

El relato de Ramiro Valencia, de 47 años de edad y presidente del Consejo de Acción Comunal del barrio El Tesoro, en Ciudad Bolívar, demuestra con su testimonio la autoproducción del espacio y la transformación progresiva del espacio que sufren los asentamientos informales debido al proceso de parcelación $(\mathrm{P})$, edificación (E) y urbanización (U) que soportan dichos sectores de la ciudad, que está en constante transformación y adaptación a las intervenciones urbanas-arquitectónicas.

Esta narración prueba — de forma sintetizada- por qué la ciudad no puede ser observada desde una realidad estática, y que las intervenciones que ocurren en ella no pueden aplicarse a un modelo abstracto fundamentado en la "dominación de la concepción de espacio y territorio como mero soporte material de las acciones humanas" (Pedrazzani, 2016, p. 366), bajo la premisa de superficie uniforme y espacio invariable, que solo puede contener la función de las actividades de los seres humanos.

De igual manera, se hace evidente que las dinámicas social y espacial deben coexistir con el fenómeno urbano, caracterizado por la "segregación funcional, la dispersión y la desaparición de la complejidad urbana» (Jacobs, 2011, p. 11), en un escenario que produce su propio espacio y tiempo, y donde existen diferentes enfoques que, en algunas ocasiones, pueden entrar en conflicto entre sí.

Por el contrario, las ciudades le apuestan a la función de los objetivos y los enfoques políticos de los gobernantes y los compromisos asumidos por estos ante la ciudadanía. Dicha responsabilidad política se convierte en el segregador por excelencia, debido a la ausencia del enfoque integrador y al desconocimiento de la continuidad de planes urbanos, así como a la falta de planificación situacional y de participación ciudadana.

No obstante lo anterior, esta necesidad de planificación urbana y de vivienda, que debería ser parte de la política pública local y, como en el 


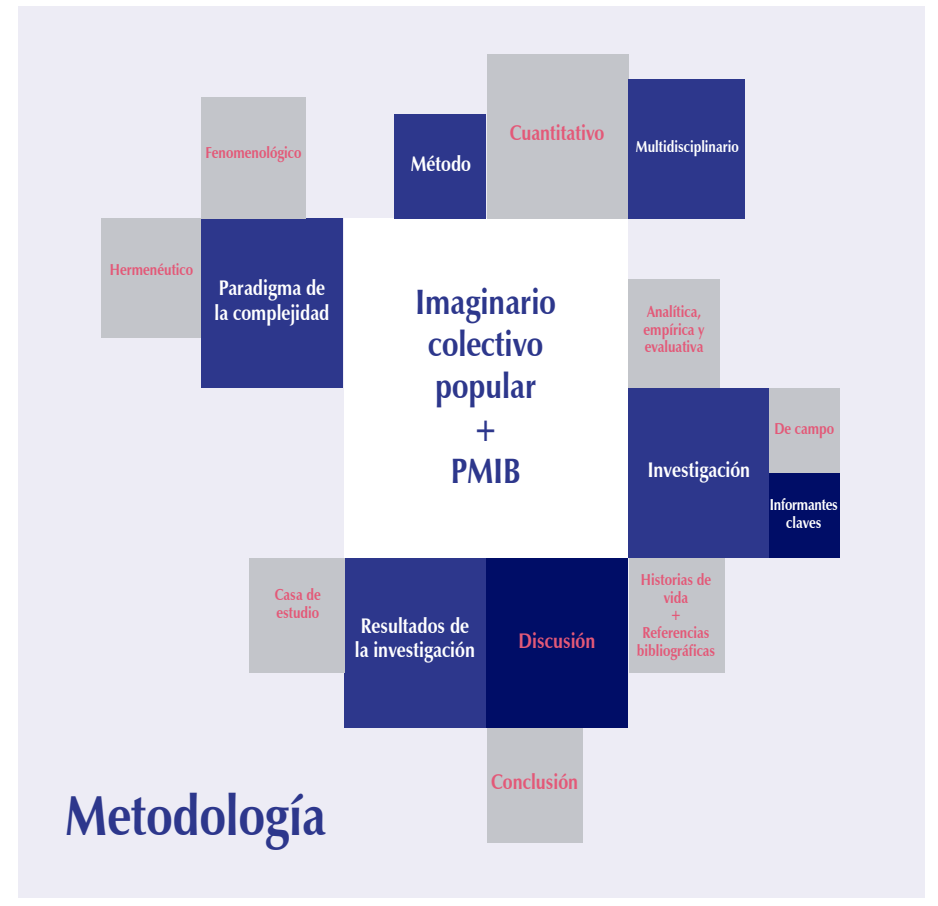

A Figura 1. Esquema metodológico.

Fuente: elaboración propia (2020). CC BY-NC-ND

caso de Ciudad Bolívar, crece y se expande de acuerdo con las posibilidades que los ojos de los recién llegados van encontrando, guiados por los primeros habitantes, que se viven en una dimensión económica, política y cultural desigual, donde los procesos económicos y tecnológicos marchan a un ritmo más rápido que los políticos y los sociales.

Pero este tejido social de participación ciudadana cuenta con sus propios valores, símbolos, creencias y costumbres, que se van enriqueciendo mientras se suman vecinos. $Y$ es a partir de ellos como se movilizan y se legitiman las acciones de los gobiernos, a quienes demandan ofrecer soluciones creativas y viables fundamentadas en las demandas ciudadanas.

\section{Metodología}

El método es el camino para el descubrimiento del conocimiento, a fin de obtener alternativas que puedan mejorar los problemas que la vida plantea. Dicho de otra manera, el método es el procedimiento por seguir para lograr los objetivos trazados en la investigación.

Para esta investigación se aplicó el método mixto (cuantitativo y cualitativo) rescatando la orientación multidisciplinaria del estudio, usando como base el enfoque fenomenológico y hermenéutico adoptando el paradigma epistemológico de la complejidad, porque las dinámicas, las interacciones sociales y las opiniones de los actores contienen en su estructura la incertidumbre como característica representativa de las agrupaciones humanas, como se expresa en la figura 1.

Al respecto, se utilizó el enfoque fenomenológico, debido a que la orientación de la investigación hacia las ciencias sociales hace necesario estudiar al individuo desde el interior, partiendo desde el fundamento de lo experimentado y lo vivido como el eje para su entendimiento; esta es la realidad que asume el presente estudio.

En cuanto al enfoque hermenéutico para la interpretación, no solo se consideraron textos escritos, sino también, el conjunto de acciones e imaginarios colectivos populares desarrollados por los habitantes del territorio en estudio, y quienes fueron sometidos a un análisis de sus formas verbales, sus conductas, sus maneras de pensar y su contexto inmediato; es decir, se tomó todo aquello que tuviera un significado y ayudara a la interpretación, de manera sistemática, del fenómeno.

Se trata de una investigación analítica, empírica y evaluativa, elaborada de forma sistemática, y en la cual se exploraron las relaciones existentes entre las variables de estudio sin tener injerencia sobre estas, y observándolas de la manera como se han dado en su contexto.

Con la aplicación del análisis se pretende establecer la relación entre el territorio y los aspectos sociales, políticos y urbanos asumiéndolos como variables que integran el proceso urbano de conformación de la ciudad, con el objeto de evaluar los procesos de PMIB y su interacción con el imaginario colectivo popular.

El diseño de investigación es de campo. Se hizo previamente una exploración bibliográfica, consistente en un análisis del conjunto de contenido teórico, representado por documentos asociados a la temática objeto de estudio. La población de la investigación se compuso a raíz del estudio de campo, considerando las historias de vida relatadas por los habitantes de las unidades de planeación zonal (UPZ) Lucero y EI Tesoro, de la localidad de Ciudad Bolívar, en Bogotá, D. C., que aportaron información clave de tipo general.

Para dicha investigación, se eligió intencionalmente a los informantes clave, mediante un conjunto de criterios que apuntaban a su representatividad:

- Tiempo de residencia en el barrio; ser fundadores.

- Sector de residencia.

- Disposición a ser entrevistados.

- Participación comunitaria en el desarrollo urbano-arquitectónico del barrio.

Se hicieron cuatro entrevistas, de las cuales se obtuvieron las historias de vida de los informantes clave, quienes fueron escogidos bajo el criterio de ser fundadores y testigos directos del proceso de crecimiento de los barrios. Es importante establecer que el tamaño de la comunidad es irrelevante para el presente estudio; algo que sí es muy importante es que la comunidad comporta un ethos común (comportamiento común o forma de vida), donde las características compartidas unen a las personas (Díaz, 2013).

La recolección de los datos obedece al registro de información pertinente sobre los atributos, los 
conceptos, las cualidades o las variables de los participantes, a fin de validar el problema planteado, se hace a partir del uso de instrumentos de investigación.

La historia de vida fue escogida por ser el reflejo de la diversidad humana, en detrimento de la homogenización y la monopolización de algunas teorías socio-urbanas existentes que se han convertido en dogmas, con base en el reconocimiento de una historia universal de Occidente.

Con la visión plural de estos relatos de los habitantes, se asume que el conocimiento se construye mediante el proceso dialéctico entre el diálogo histórico y el aprendizaje comunitario producido por los grupos sociales y el investigador, fundamentado, a su vez, en la observación, la interpretación y el análisis crítico de la realidad del objeto de estudio.

Para reconstruir los relatos de los barrios $\mathrm{El}$ Tesoro, Cordillera del Sur y Naciones Unidas, se conversó en 2016 con los fundadores seleccionados de estos barrios, quienes aceptaron participar a través de historias de vida.

La recuperación de estas memorias orales se convirtió en la herramienta metodológica más productiva para culminar esta investigación, que se orientó con una perspectiva de interpretación del hábitat individual y colectivo; de la defensa de los Derechos Humanos; de la revaloración de la autoconstrucción de la vivienda y el paisaje urbano; de la reconstrucción de la relación entre Estado y comunidad a través de los PMIB; de la recuperación de los valores populares, y del entendimiento de la vida cotidiana en los barrios informales de Ciudad Bolívar, en Bogotá, D. C.

Al respecto, las conclusiones alcanzadas no solo son el resultado de la especulación de naturaleza conceptual, sino que también estuvieron fundamentadas en las representaciones sociales y territoriales de los habitantes de los sectores objeto de estudio.

\section{Caso de estudio: contexto espacial}

La capital de Colombia fue la escogida para realizar esta investigación porque un alto número de su población habita asentamientos irregulares; es una ciudad marcada por altos índices de desigualdad espacial y social.

Otro de los elementos clave fue la selección de los barrios, pues los considerados para el estudio debían cumplir con los siguientes aspectos: 1) tener como proceso de origen la urbanización pirata, 2) ser beneficiarios de los PMIB y 3) estar localizados en la localidad de Ciudad Bolívar, por tener facilidad de acceso a la información.

También se omitieron los barrios desarrollados por organizaciones no gubernamentales (ONG) o entidades públicas, pues se perdería el verdadero enfoque de la investigación, debido a que en esos barrios excluidos existe una presencia del Estado desde su inicio, lo cual corresponde a otro proceso de ocupación del suelo y no generan datos relevantes para este análisis.

Para el caso de esta investigación, se escogieron los barrios Naciones Unidas, El Tesoro y Cordillera del Sur, pertenecientes a la UPZ Lucero, y localizados en Ciudad Bolívar. Esto facilitó el acceso a la comunidad, cuyos integrantes tienen como característica común sus propias historias de origen, a su vez, conformadas por el tejido social de las semblanzas personales de sus habitantes que, en conjunto, dibujan el "imaginario colectivo popular". Otro factor relevante es el proceso de ocupación mediante la urbanización pirata, para luego ser legalizados como barrios.

Por último, fue la aplicación de PMIB durante la alcaldía de Gustavo Petro en el periodo 2012 2015, con una inversión de 17826749 447,29 pesos, información suministrada por la Secretaría Distrital del Hábitat de la Alcaldía Mayor de Bogotá (2015).

\section{Aproximación conceptual al imaginario colectivo popular}

Las representaciones sociales de los barrios informales son el resultado de normas culturales implícitas, caracterizadas por el comportamiento individual y comunitario, donde se construyen tejidos sociales. "Si no existe la relación social no hay espacio" (Lefebvre, 2013, p. 14), lo cual indica que dicho espacio es un producto social, como afirma este autor y se comprueba en esta narración:

\begin{abstract}
Mi vivienda es propia, se la compré a mi hermano. El rancho estaba construido de zinc y sólo tenía un espacio interior el cual era usado como sala, cocina y habitación. Con nuestro trabajo (suyo y de su pareja) pudimos levantar la casita poco a poco. Lo primero fue construir la sala y luego la cocina y acondicionar una alcoba; por último, construimos la plancha y el resto de techo es en zinc. El precio del lote con el rancho fue de 200.000 pesos... representaba el sueño de tener nuestra casa propia. (M. Camacho, comunicación personal, 15 de agosto de 2016)
\end{abstract}

Este relato de vida resume en pocas líneas el valor del término imaginario colectivo popular, donde se plantea esa idea central de fabricación de una imagen visible y la abstracción de un significado-significante contenida en la memoria de los actores sociales que ocupan un espacio determinado (Reyes, 2020).

Según Tavares y Fitch (2019), tal proceso se compone de la "comunidad o red de relaciones", la cual se puede definir como la variedad de puntos (que son las personas o los grupos sociales), conectados por las líneas (que indican las interacciones entre las personas o grupos), que derivan de las características comunes que "provienen de orígenes compartidos (parentesco, tribu, historia o lugar); características o actividades similares, como la economía, las interacciones o las estructuras sociales: o actitudes, comportamientos y propósitos similares" (Díaz, 2013, p. 161). 

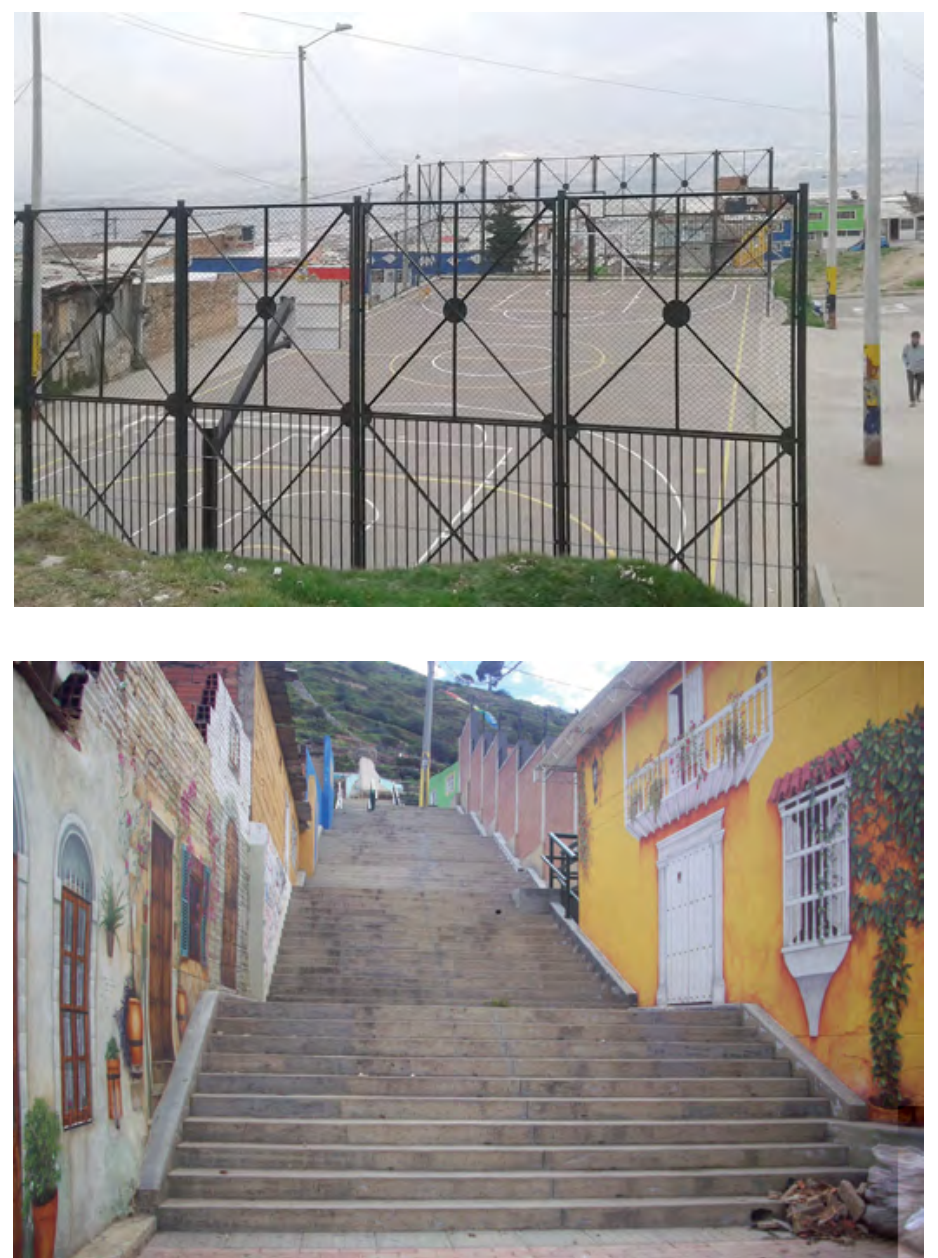

(A) Figura 2. Intervenciones urbanas realizadas dentro de los PMIB en la UPZ 67 Lucero, de Ciudad Bolívar, Bogotá D. C

Fuente: elaboración propia (2019). CC BY-NC-ND
Otro aspecto que se interpreta es el "fenómeno de auto-eco-organización extraordinariamente complejo que produce la autonomía" (Morin, 2009, p. 32) como mecanismo de empoderamiento espacial/social.

Por otra parte, lo colectivo ha estado ligado a las políticas públicas nacionales e internacionales en el tema del desarrollo comunitario. Para la doctora Noriko Hataya, citada por Díaz (2013), el término comunidad produce objetivos comunes de desarrollo vinculados al mejoramiento de la calidad de vida que se convierten en el medio de promoción del desarrollo local como principal mecanismo de los gobiernos.

El papel unidireccional que asume el urbanismo contemporáneo (políticas territoriales y planificación urbana) desconoce el territorio, la territorialidad, y la territorialización (Jolly, 2016), para convertirse en árbitro entre las diferentes fuerzas o reparar los excesos o las disfunciones producidas por las intervenciones urbanas, como instrumento ordenador del caos y la incertidumbre propios de la ciudad.

\section{Dialéctica de los PMIB}

Diversos países han volcado sus políticas en el desarrollo de acciones de mejoramiento barrial que han generado la formulación de programas de intervención. En el siglo XXI, los PMIB se caracterizan por reconocer la participación ciudadana y las urbanizaciones informales como una solución que minimiza el impacto social, económico y ambiental, debido a que mantienen el entramado comunitario (cohesión social) en sus sitios originales, situación que genera la identidad y la apropiación de las acciones, así como la sostenibilidad socioespacial de las intervenciones.

Es necesario resaltar que los países latinoamericanos que han acogido dentro de sus políticas públicas los PMIB se convirtieron, en el ámbito socio-urbano, en la oportunidad para generar intervenciones urbanas-arquitectónicas en los barrios informales, con la esperanza de que fuesen legitimados como barrios citadinos, y así contar con sistemas urbanos necesarios para la integración social/espacial y mejorar la calidad de vida individual y colectiva de los habitantes, tras el propósito de la superación de la pobreza en todas sus formas como el primero de los Objetivos de Desarrollo Sostenible (ODS).

Con el presente estudio se logra ampliar la visión de los PMIB no solo desde el beneficio generado por la intervención espacio-urbana, sino incluyendo la representación social/espacial de los actores sociales, que evidencia su pensamiento y su realidad colectiva urbana como preexistencia de su origen territorial por autoproducción de sus habitantes, tal cual se muestra en la figura 2, como un proceso ajeno a la política, con planificación estratégica y otorgamiento de garantías del Gobierno nacional, como responsable constitucional de proteger y garantizar los "derechos ciudadanos como una forma de planificación urbana a través del diálogo y participación" (Tavares y Fitch, 2019, p. 25).

También se estableció como visión, considerar las políticas públicas urbanas interpretadas como una territorialización; es decir, como las acciones de intervenciones en un espacio material (territorio) que producen la actualización del sistema de valores que la fundamentan (territorialidad), un sistema compuesto por las representaciones y los significados del territorio como elemento que condiciona material y socialmente las acciones y las intervenciones que se originen (Jolly, 2016).

\section{Acotaciones conceptuales de los PMIB}

La institucionalización del PMIB en Bogotá tiene su punto de ignición en el 2000, con su integración al Plan de Ordenamiento Territorial (POT) (POT, Decreto 619 de 2000). En el artículo 109 del POT se conformó la política de vivienda y hábitat, que tiene como objetivo que el PMIB se formule como estrategia para mejorar la calidad de vida de la población que habita esos sectores. El objetivo del PMIB se relaciona con

\footnotetext{
Orientar las acciones de complementación, reordenamiento o adecuación requeridas tanto en el espacio urbano como en las unidades de vivienda que conforman los asentamientos de origen informal ubicados en la periferia de la ciudad. Lo anterior para corregir las deficiencias físicas, ambientales y legales generadas por su origen fuera de las normas urbanas y permitir que sus habitantes accedan a la calidad de vida urbana definida para el conjunto de la ciudad. (Secretaría Distrital del Hábitat, 2016, p. 9)
} 
La Alcaldía Mayor de Bogotá, a través de la Secretaría Distrital del Hábitat (SDHT), lidera la ejecución de intervenciones relacionadas con el mejoramiento de la condición física del barrio. También gestiona las acciones integrales sociales con participación ciudadana, para la institucionalización de espacios de encuentro en el ámbito de barrio, como elemento clave para el empoderamiento social.

Estas actuaciones urbanas son implementadas sobre un modelo de intervención en las UPZ, con el tratamiento de Mejoramiento Integral, a través de un nivel de intervención territorial denominado las Áreas Prioritarias de Intervención (API).

Las API se constituyen en las zonas más deficitarias de cada UPZ, teniendo en cuenta las problemáticas allí encontradas a partir de los componentes del mejoramiento integral; es decir, servicios públicos, accesibilidad, equipamientos sociales, equipamientos recreativos $y$ culturales, condiciones ambientales y vivienda.

Por ende, una vez llevado a cabo el diagnóstico en cada territorio, se plantea la propuesta específica de intervenciones y se hace la coordinación interinstitucional para garantizar la ejecución de dichas acciones y su respectiva sostenibilidad.

Una vez definida la organización de la periferia urbana, se inician largos procesos de adecuación de terreno, instalación de redes de servicios básicos, construcción de equipamientos y titularización de predios, a fin de transformarse en barrios legales conformados por redes socioeconómicas dinámicas.

La legalización de los barrios, después de 20 o 30 años de fundados, es el resultado de la organización de colectivos sociales y promotores de cooperación, que cumplen funciones de gestores de proyectos o recursos ante los gobiernos municipales o nacionales, así como de ONG.

\section{Resultados}

Entre los resultados obtenidos es importante precisar que, para los habitantes de los sectores informales, la casa representa mucho más que su sentido arquitectónico y antropológico de morada o albergue, ya que la vivienda fue construida por sus propios habitantes. Por tal motivo, representa la identidad y la aprobación, y cuenta con múltiples valoraciones, así como lecturas de la cotidianidad familiar y comunitaria.

Este fenómeno es simbolizado desde el inicio por la compra del predio pirata y sin servicios. Posteriormente, se lleva a cabo el proceso de ocupación del predio, mediante la autoconstrucción progresiva de la vivienda, con una cobertura de servicios públicos incompleta y una infraestructura vial inadecuada, como consecuencia de los aspectos físicos y ambientales del terreno.
El principal motivo para migrar hacia la ciudad de Bogotá fue que éramos varios hermanos y desde los 15 años me tocó salir a trabajar; y desde esa época vivo aquí. Hace 24 años cuando llegué, ya más o menos había viviendas. Yo compré mi lote, que me salió en 800.000 pesos, a un señor, el cual me entregó como documento del negocio una promesa de compraventa y ese es el documento que tengo actualmente, porque no he hecho escrituras. Cuando compré el lote solo tenía unas cuantas paredes en bloque; luego, compré unas puertas y tejas para hacer una enramada y el piso fue sagradamente en tierra. Así fue como comencé a vivir aquí, toda la construcción fue con recursos propios. (A. Martínez, comunicación personal, 1 septiembre de 2016)

Con su historia, esta residente demuestra cómo la autoconstrucción se vuelve el principal mecanismo de acceso a la vivienda, no obstante estar fuera de marcos legales y reglamentos, pero resulta otra manera clave de proporcionar vivienda desde el enfoque fenomenológico, como la concepción humana de garantizar una vivienda propia familiar a la medida de sus ocupantes, rompiendo con los aspectos funcionales y formales impuestos por el postulado arquitectónico (economía, área construida, estandarización técnica, espacial y estética).

La autoconstrucción de viviendas y espacios urbanos es el producto del esfuerzo comunitario, detonante para la creación o el fortalecimiento del mercado inmobiliario informal, operado por ciudadanos y líderes comunitarios convertidos en los gestores de la ocupación de terrenos aislados y no urbanizados — privados o públicos-, quienes luego se reparten los predios entre líderes, organizadores y tomadores de la invasión. Por último, se inicia la etapa de comercialización, o venta pirata de predios, que deja ganancia económica mediante la venta informal de predios no urbanizados.

Ángel Tapia llegó a la localidad de Ciudad Bolívar en 1983, cuando, con su entonces novia, se movilizó desde Tolima para radicarse en la capital, con el propósito de "salir adelante" como no podría hacerlo en su ciudad natal. Bogotá le ofrecía la oportunidad de conseguir su propia vivienda, el asiento de su futuro hogar.

\section{En esta parte no había nada... era un potrero. No teníamos ni agua ni luz... nos tocaba alumbrar con espermas (velas). El agua nos tocaba traerla del barrio La Estrella en el hombro; no había burro, los burros éramos nosotros mismos. (A. Tapia, comunicación personal, 6 de septiembre de 2016)}

Este testimonio, igualmente, refleja la integración del imaginario popular de los habitantes de barrio con la expansión y las características propias de su área de residencia, donde han generado - con carencias y dificultades, y a su propio ritmo- su adaptación y su modelamiento como grupo ciudadano.

Así mismo, expone cómo, durante décadas, las políticas públicas han implementado programas que resultaron no solo insatisfactorios ante 
la progresiva demanda de viviendas, dotaciones y equipamientos en estas zonas, sino la razón por la que se hace imprescindible integrar la participación de sus habitantes en los PMIB.

Este escenario se compone por dos limitantes: la primera es la visión fragmentada que se produce al designar momentos específicos para la participación ciudadana durante el desarrollo del programa o el proyecto, y así causar la pérdida del empoderamiento social por parte de los habitantes y reducir la eficiencia de las acciones con respecto a la verdadera realidad comunitaria.

En segundo lugar, se da, en algunos casos, la práctica parcial de la participación, pero esto genera una reducción en el acceso a información y se niega la posibilidad de que el colectivo tome decisiones sobre su futuro y cuente con los recursos necesarios para ver cristalizadas sus propuestas.

Esta situación ocasiona la pérdida de la capacidad para "leer" el lugar e identificar los puntos críticos que deben ser abordados por las acciones de los PMIB, y ello causa un punto de ruptura con el imaginario colectivo popular de los habitantes.

Durante la etapa de evaluación y seguimiento del PMIB, es el momento donde se reduce la participación ciudadana, como consecuencia de la lógica lineal que promueve una participación negativa, debido a que estimula la creación de pequeños grupos de veedores de la propia comunidad, que son los encargados de rendir cuentas sobre la evaluación priorizando el interés personal por encima del beneficio de la comunidad, lo cual genera divisiones y confrontaciones (Torres et al., 2009).

Al respecto, Díaz (2013) refiere que estos pequeños grupos ciudadanos se convierten en clientelistas, manipulados a menudo por los dirigentes políticos que requieren votos a favor, como moneda de cambio por proyectos insertos en la administración pública.

\section{Discusión}

\section{Aproximación a los PMIB desde el imaginario colectivo popular}

Cuando se observa, específicamente, en el panorama urbano del sector sur de Bogotá, D. C., cobran mayor importancia las edificaciones de bloques de cemento o arcilla y con cubiertas de zinc, las cuales se convirtieron en la supermuralla que integra a estas casas con los terrenos inclinados.

Los imaginarios colectivos populares permiten interpretar y comprender la información genética de la conformación, la consolidación y la red de funcionamiento concebida en la epistemología popular de sus propios habitantes, expresada en los diferentes procesos urbanos sobre el territorio, que se superponen y se transversalizan en el espacio y el tiempo.

\section{Componente de \\ mejoramiento}

\section{Subcomponentes}

\section{Alcaldía local SDHT}

\section{Intervenciones estatales}

SCRD

ETB

\begin{tabular}{|c|c|c|c|c|c|c|c|}
\hline 1. Servicios públicos & Teléfonos & & & & \multicolumn{3}{|c|}{3.452 .000} \\
\hline \multirow{3}{*}{ 2. Accesibilidad } & Vías peatonales & & & & & & \\
\hline & Andenes & & & & & & \\
\hline & Vías locales & 271.192 .683 & & & & & \\
\hline \multirow{3}{*}{ 3. Equipamientos sociales } & Educación & & & & & & \\
\hline & Fortalecen común & & & & & & \\
\hline & Salud & & & & & & \\
\hline \multirow{2}{*}{$\begin{array}{l}\text { 4. Equipamientos } \\
\text { cívicos y culturales }\end{array}$} & Parques & & & & & & \\
\hline & Incentivos culturales & & & 10.000 .000 & & & \\
\hline \multirow{2}{*}{$\begin{array}{l}\text { 5. Condiciones } \\
\text { ambientales }\end{array}$} & Recuperación quebradas & & & & 5.760 .000 .000 & & 3.306 .555 .697 \\
\hline & Gestión ambiental & & & & 84.399 .284 & & \\
\hline \multirow{2}{*}{$\begin{array}{l}\text { 6. Condiciones de la } \\
\text { vivienda }\end{array}$} & $\begin{array}{c}\text { Mejoramiento de vivienda } \\
\ldots \ldots \ldots \ldots \ldots \ldots \ldots \ldots \ldots \ldots \ldots \ldots\end{array}$ & & & & & & \\
\hline & Barrios de colores & & 3.350 .900 & & & & \\
\hline \multicolumn{2}{|l|}{ Total } & 271.192.683 & 3.350 .900 & 10.000 .000 & 5.844.399.284 & 3.452 .000 & 3.306.555.697 \\
\hline
\end{tabular}


A partir del análisis comparativo en la tabla 1 , se puede establecer que el programa de mejoramiento integral de barrio ejecutado por diferentes entidades distritales en la UPZ Lucero en el periodo 2012-2015 estaba representado por seis componentes: 1) servicios públicos, 2) accesibilidad, 3) equipamientos sociales, 4) equipamientos de servicios y culturales, 5) condiciones ambientales y 6) condiciones de la vivienda.

En primer lugar, se puede observar que existen una mayor inversión presupuestaria y más ejecución de proyectos sobre el componente de condiciones ambientales en el área de recuperación de quebradas y gestión ambiental, obras ejecutadas por la Secretaría Distrital de Ambiente (SDA).

En segundo lugar, se hallaron las inversiones presupuestales y la ejecución de proyectos en los componentes de accesibilidad en las áreas de construcción y recuperación del espacio público sobre los andenes del sector, las vías peatonales y el mejoramiento de vivienda, proyectos ejecutados por la Caja de Vivienda Popular. En tercer lugar, se encontraron las inversiones hechas de nuevo sobre el componente de condiciones ambientales en el área de recuperación de quebradas, obras realizadas por la Empresa de Acueducto de Bogotá.

Se puede determinar que el programa de mejoramiento integral de barrio de dicha UPZ cuenta con una inversión de 9150954981 pesos, lo que representa el $51 \%$ del presupuesto total de programa de MIB de la UPZ Lucero, debido a la importancia de solucionar las problemáticas ambientales y la recuperación de los cuerpos de agua del sector.

En cuarto lugar, se encontró que los proyectos ejecutados en los componentes de accesibilidad y condiciones de la vivienda, con una inversión por 5534892871 pesos, lo que representa el $31 \%$ del presupuesto total (Secretaría Distrital del Hábitat, 2015). Por último, encontramos los proyectos relacionados con el resto de los componentes del PMIB, que representan el $18 \%$ del presupuesto total.

Al respecto, la SDHT, para la intervención del API de Lucero, desarrolló intervenciones urbanas-arquitectónicas a través de la ejecución de los proyectos que se detallan a continuación, a partir de los componentes del PMIB, con un costo de 17826749447,29 pesos (Secretaría Distrital del Hábitat, 2015).

\section{Accesibilidad}

A través del Convenio Interadministrativo $\mathrm{N}^{\circ}$ 303 de 2013, suscrito entre la SDHT y la Caja de Vivienda Popular (CVP), se ejecutaron 33 segmentos viales (escaleras, vías y andenes). Las experiencias de intervención de este sector se encuentran marcadas por los trabajos participativos con la comunidad, como talleres de cartografía social de los tramos viales que se van a intervenir por parte de la CVP, en un ejercicio de diseño participativo con el fin de buscar apropiación y corresponsabilidad de las intervenciones priorizadas.

Al respecto, el relato de Ángel Tapia explica cómo las vías de acceso en los barrios informales se vuelven un componente clave en constante intervención para el mejoramiento del sistema vial local y su integración con el de la ciudad. También resalta que el componente de accesibilidad es el principal mecanismo para romper la fragmentación socioespacial de los habitantes.

Para el trazado de las vías, cada habitante tomaba la decisión de por dónde pasarían, según la ubicación de cada una de las casas; fue un trabajo de la comunidad, sin ninguna guía de autoridades o profesionales. Las vías del barrio eran trochas, caminos de arena. En relación con el transporte, nos tocaba hasta el barrio Lucero Alto, donde existía un paradero de bus, para esta zona no llegaba y nos tocaba caminar hasta este paradero o hasta el barrio La Estrella baja. (A. Tapia, comunicación personal, 6 de septiembre de 2016)

La narración de Ramiro Valencia, sin embargo, evidencia la segregación socioespacial que continúa inserta en el imaginario colectivo de los ocupantes de estos territorios, lo que fractura la cohesión social como variable principal en la conformación de ciudades compactas del siglo XXI.

Nosotros tenemos tan mala reputación en la ciudad, porque es Ciudad Bolívar, pero aquí también hay gente que sabe leer, hay gente que sabe hacer muchas cosas, la mayoría del personal que trabaja en Bogotá es de Ciudad Bolívar... nosotros pagamos impuestos y necesitamos de todo, igual en el sur y el norte. Aquí también construimos con bloque y ladrillo. Yo no sé cuál es la diferencia [...] claro, porque en el norte hay gente que tiene dinero; pero igual somos colombianos todos, es lo que el Gobierno no detalla con la periferia de la ciudad. (R. Valencia, comunicación personal, 3 agosto de 2016)

\section{Servicios públicos}

Para ilustrar mejor la situación de los servicios públicos en el proceso de ocupación de Ciudad Bolívar, es necesario retomar la narración de Ángel Tapia, que nos traslada de nuevo al momento de la fundación del barrio El Tesoro, en 1983, y donde prueba cómo fue la autoconstrucción de los servicios públicos para cubrir la demanda de las viviendas.

\section{El servicio público de luz no existía, eran instala- ciones improvisadas por medio de unos alambres de púas, duramos alrededor de 15 años alum- brando de esa manera, después llegó la luz y luego, el agua. (A. Tapia, comunicación personal, 6 de septiembre de 2016)}

Como se ya refirió, en el caso del agua potable, esta se comenzó a distribuir por mangueras desde albercas en la vereda de Quibá. Luego vino la instalación de un tanque comprado a Ecopetrol, que se transformó en el sitio principal del barrio para albergar reuniones y hasta disputas entre vecinos. 
Este punto se consolidaría como el de distribución del agua, nuevamente, a través de mangueras, las cuales llegaban a unas pilas ubicadas cada tres o cuatro cuadras. Así, cada sector contaría con el servicio durante dos o tres horas, aproximadamente. Gómez (2014) alcanza a precisar el proceso de desarrollo del servicio del agua, como aspecto principal para la consolidación del barrio:

Finalmente fue la participación del alcalde mayor en una asamblea con la comunidad, la que garantizó la llegada del agua potable, ya que al aceptar este un vaso de agua de Quibá, cayó enfermo y permaneció varios días hospitalizado. Poco después, tres motobombas fueron instaladas para subir hasta el barrio agua tratada. Para el cocinar, se construyeron en cada sector casetas donde dos o tres veces por semana era expendido el combustible. La energía se 'contrabandeaba' de Candelaria La Nueva, IV Etapa y las redes se iban subiendo poco a poco desde las partes bajas hacia las más altas. Este procedimiento recargaba los transformadores y se producían con frecuencia apagones. La luz que llegaba era de bajo voltaje. (p. 69)

Al respecto, el relato de Ana Beatriz Martínez demuestra que, para 1995, las viviendas de la localidad de Ciudad Bolívar contaban con servicios públicos de energía eléctrica y agua.

Cuando llegué al sector hace 24 años, había servicio de luz y el agua llegaba por medio de una manguera, ya no cargaban agua; solo cuando no mandaban agua en la manguera, tocaba salir a buscar a los barrios de la parte baja. (A. Martínez, comunicación personal, 1 de septiembre del 2016)

No obstante, para el periodo 2012-2015 se pudo observar que el PMIB se enfoca en mejorar la calidad de servicio público de internet y limpieza del desagüe de agua, situación que prueba cómo estos barrios superaron los problemas eléctricos y de agua. Se llevó a cabo la optimización en tres gabinetes de la Unidad Remota de Banda Ancha (URBA), mediante la ampliación o el mantenimiento de equipos por parte de la Empresa de Teléfonos de Bogotá (ETB), con el fin de mejorar la velocidad del servicio en el sector, como se muestra en la figura 3 .

\section{Equipamientos sociales}

En el Instituto de Educación Distrital (IED) José Jaime Rojas y en el IED El Tesoro, La Cumbre, se implementaron programas de escuelas de formación (material didáctico), conectividad (Proyecto 30 Megas Internet) y alimentación escolar, para beneficiar, aproximadamente, a 1500 estudiantes. En el IED José Jaime Rojas, el Fondo de Desarrollo Local (FDL) llevó a cabo las obras de mitigación requeridas en aras de garantizar la seguridad de la comunidad educativa por situaciones de riesgo. Adicionalmente, la SIS atendió, aproximadamente, a 300 adultos mayores y niños en el comedor comunitario y asignó 180 cupos en el Jardín Infantil Naciones Unidas.
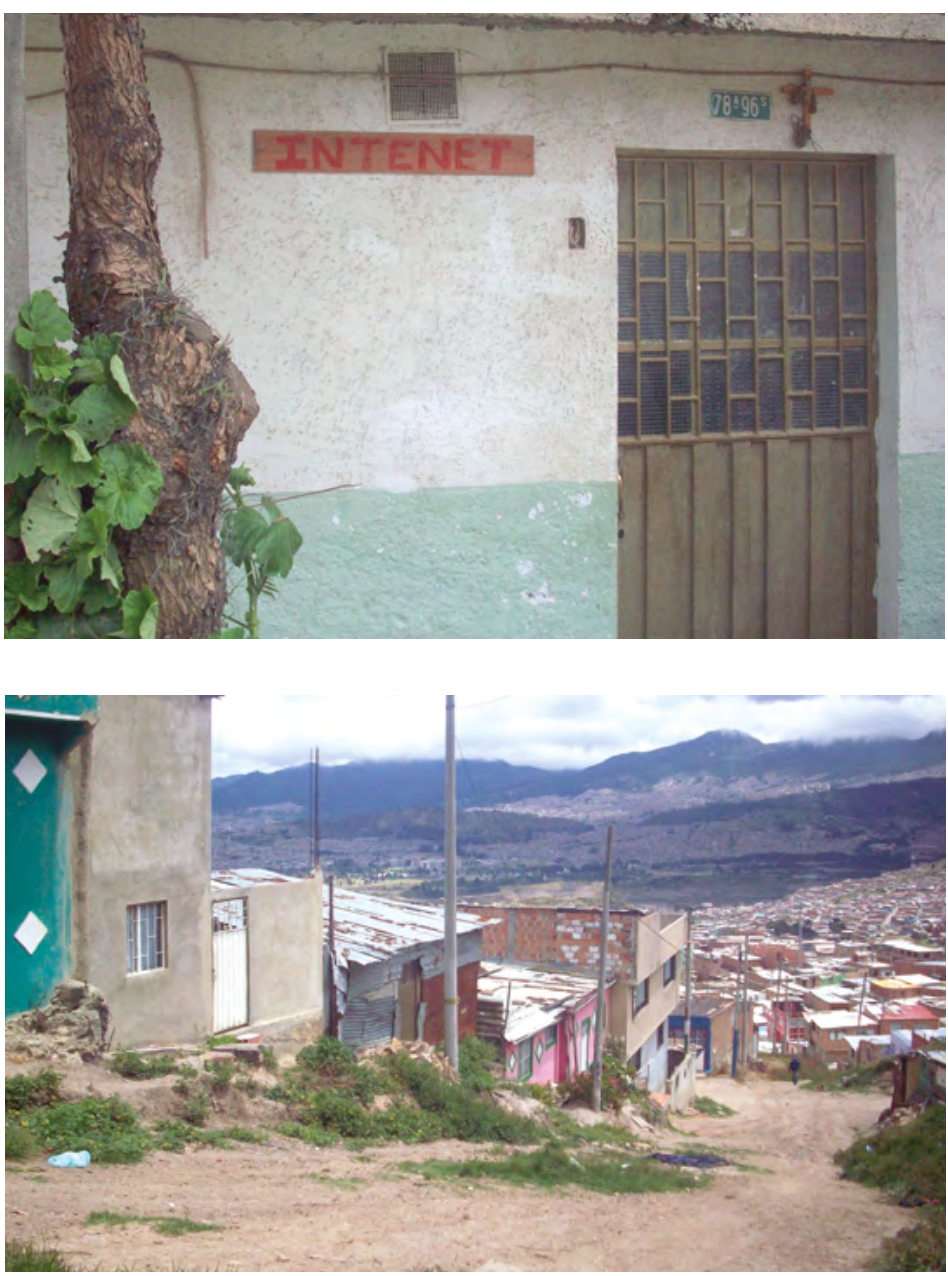

Cuenta Ana Beatriz Martínez que "los equipamientos de mayor uso en el barrio son los colegios, porque con mercado no contamos, solo tenemos tiendas de barrio. Me gustaría que existiera más unión en temas de comunidad y tener más cerca los centros comerciales, no tener que salir de la localidad para acceder a un parque" (A. Martínez, comunicación personal, 1 de septiembre de 2016). Este relato confirma que el desarrollo de la zona también se encuentra ligado a la capacidad de autogestión de la comunidad. Y conseguir la regularización y construcción de equipamientos educativos continúa siendo prioritario dentro las acciones de los PMIB.

\section{Condiciones individuales de vivienda}

Al comienzo, la vivienda se caracteriza por sus precarias condiciones espaciales y técnicas: están hechas de madera, metales o desechos, para, simplemente, manifestar la ocupación del predio. Luego, en un lapso de entre cinco y 15 años, la casa experimenta mejoras en sus condiciones físicas y habitacionales (figura 4).

Y aunque la vivienda es la célula principal de los asentamientos informales en el desarrollo de la ocupación del territorio, no representa la categoría de mayor importancia para los habitantes y no contiene una relación fractal. Se puede establecer que la autoconstrucción de la vivienda popular puede convertirse en un proceso de por vida para sus habitantes.

Adicionalmente, aparecen la ampliación o la división de la vivienda con fines productivos, bien sea por medio del alquiler de locales
A Figura 3. Servicio de internet.

Fuente: elaboración propia (2019). CC BY-NC-ND

A Figura 4. Viviendas precarias de la localidad de Ciudad Bolívar.

Fuente: elaboración propia (2016). CC BY-NC-ND 
comerciales, habitaciones o, incluso, viviendas completamente nuevas, con el fin de aumentar los ingresos familiares.

Al respecto, el relato de Ramiro Valencia comenta, sobre el proceso de desarrollo urbano del barrio, que "hace más o menos entre dos y tres años, la Caja de Vivienda Popular ha venido realizando mejoramientos de viviendas del barrio; como yo soy constructor, mi aporte ha sido ayudar en la construcción y mejoras de viviendas; y en la actualidad todavía me encuentro trabajando en la red de constructores de la Caja de Vivienda Popular" (R. Valencia, comunicación personal, 3 de agosto de 2016).

Para 2015 se hizo la intervención de 170 fachadas y 2 salones comunales, dentro del marco de la estrategia denominada "Barrios de Colores", que realiza la SDHT; adicionalmente, se ejecutaron 2 proyectos por el esquema territorial dirigido para subsidio distrital de vivienda. Cabe destacar que se hizo un trabajo conjunto con la CVP para la gestión en el territorio y la identificación de viviendas susceptibles de mejoramiento de vivienda en sus condiciones de habitabilidad, tal cual muestra la figura 5.

\section{Equipamientos de actividades cívicas y culturales}

A través del Convenio Interadministrativo $\mathrm{N}^{\circ}$ 360 de 2013, suscrito entre la SDHT y el Instituto Distrital de Recreación y Deporte (IDRD), se encuentra en proceso de ejecución la construcción de dos parques: código IDRD 19-633 Naciones Unidas y código IDRD 19-291 urbanización Serranía. "Lo único que nosotros tenemos son pequeñas canchas que están siempre ocupadas por adultos y jóvenes, nunca tienen oportunidad los niños pequeños de jugar", como relata Ana Beatriz Martínez (comunicación personal, 1 de septiembre del 2016).

(v) Figura 5. Intervención de fachadas de vivienda de la localidad de Ciudad Bolívar. Fuente: elaboración propia (2016). CC BY-NC-ND
Se infiere, entonces, que las políticas públicas han vuelto visibles los sectores populares con la aplicación de subsidios, como las nuevas formas de generar control y disciplina (Zibechi, 2007).

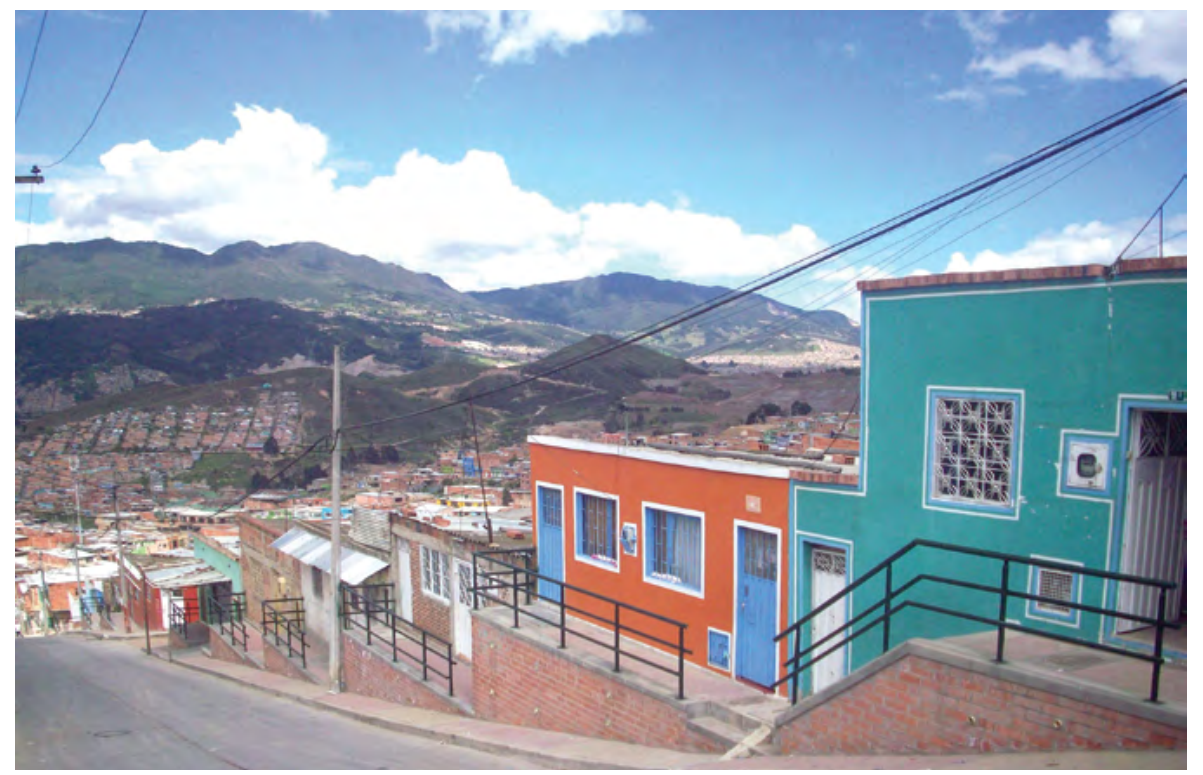

Hay que romper con el paradigma de aproximación lineal "de arriba hacia abajo", y cambiarlo por el de "de abajo hacia arriba", donde el papel principal de los profesionales sea ayudar a generar, filosofar y guiar esta complejidad evolutiva (Salingaros, 2004).

Al respecto, los autores Torres et al. (2009) establecen que dentro de la dinámica del sistema de PMIB está la participación ciudadana como mecanismo de capacidad e incidencia comunitaria para la definición y la orientación de las políticas del Estado. Dicha participación se puede producir mediante la delegación como principal base de la democracia representativa, que busca alternativas para solucionar los problemas comunitarios y su inclusión como estrategia de desarrollo.

No obstante lo anterior, siguen existiendo fragmentaciones y limitaciones en la participación ciudadana, lo cual deja al imaginario colectivo popular marcado por la segregación física y social. El futuro de la organización comunitaria está representado por la autonomía en las decisiones relacionadas con las necesidades y las potencialidades, mediante la intervención en la gestión, la planificación y la ejecución de proyectos.

\section{Conclusión}

A través del desarrollo de la investigación se ha evidenciado que la relación existente entre las actuaciones del Estado en las urbanizaciones informales por medio de los PMIB, con el imaginario colectivo popular de sus habitantes como constructo de las intervenciones urbanísticas, está fundamentada por la participación ciudadana como principal mecanismo para alcanzar mejores resultados del proyecto y el empoderamiento como proceso que eleva la calidad vida y facilita el cambio social, y que, además, beneficia a la población desfavorecida.

En el caso de la ciudad de Bogotá, en los años noventa del siglo XX se introdujo el concepto de la planeación participativa produciendo la generación de proyectos dentro de las comunidades. Las reuniones y las asambleas comunitarias se convirtieron en el principal espacio para la toma de decisiones. Pero, con el pasar de los años, perdieron la participación positiva de los habitantes, por la falta de voluntad política de los gobernantes.

Con la perspectiva de los PMIB, persiste una dicotomía en su carácter de intervención de territorio desde un enfoque social o físico-espacial, situación que genera fragmentación en la ejecución de los proyectos de mejoramiento de los sectores informales que son adelantados por las diferentes instituciones gubernamentales, lo cual pone en duda su carácter integrador, al romper con el paradigma complejo que deben contener la política pública urbana. 
Ni lo físico-espacial ni lo social deben estar represados por una competencia interna de los PMIB; por el contrario, deben mantener un equilibrio, representado por la eficiencia, la funcionalidad y el empoderamiento del conjunto de acciones.

Se puede observar, sin embargo, que en el PMIB implementado en la UPZ Lucero durante el periodo 2012-2015 se hizo una alta inversión económica, pero se mantuvo la competencia en la definición del enfoque, y fue lo social el eje de esta experiencia; dejando a un lado la vitalización, la legitimación y la operatividad de proyectos fundamentados en la rentabilidad económica. De igual forma, el hecho de que se construyan infraestructuras no debe significar la ausencia de bienestar para la población.

Por otra parte, los PMIB no pueden seguir siendo acciones complementarias: se tienen que transformar en acciones estratégicas para la ciudad, escenario poco valorado por las instituciones gubernamentales. En cambio, las instancias internacionales valoran el carácter estratégico de los PMIB como herramienta para el desarrollo urbano y potenciador de la economía, mediante la generación de créditos como una determinante para centrar y orientar las políticas urbanas.

Muchos de los habitantes que relataron sus historias de vida demuestran que aprendieron cuáles son sus derechos como ciudadanos, lo cual desencadena la exigencia de mejores servicios y el desarrollo de la infraestructura como bienestar humano, y donde la vivienda es el principal eje de desarrollo familiar, a través del mejoramiento de sus condiciones físicas de habitabilidad. Esto se convierte, en algunos casos, en ingreso económico adicional, como consecuencia del arriendo o de los fines comerciales de algunos espacios, como una fuente de ingresos para la economía familiar.

Se puede inferir que existe una relación directa entre el imaginario colectivo popular de los habitantes de los sectores y los planes de mejoramiento integral de barrio, compuesto por la capacidad de interacción entre los diferentes actores de la comunidad y su alto interés en manifestar sus necesidades físico-espaciales y sociales, las cuales son inherentes a la vida colectiva, representada por el conjunto de experiencias individuales y colectivas.

También queda demostrado que, dentro de los fundadores de los barrios, se mantiene un imaginario colectivo popular del modelo urbano que planificaron al inicio del proceso de ocupación del sector, manteniendo algunos aspectos urbano-arquitectónicos que se han articulado con las intervenciones de PMIB desarrolladas por las instituciones del Estado.

Otro aspecto para resaltar en los relatos de vida es que evidenciaron la sincronización de la red comunitaria para la organización y la participación en el desarrollo de la política pública, como mecanismo para legitimar las acciones del Estado en el mejoramiento de su calidad de vida, cuyo principal soporte es el progreso en su capacidad de negociación con las autoridades para la gestión de proyectos.

Finalmente, los habitantes demostraron fuertes lazos comunitarios, soportados en lo que la socióloga Norika Hataya denomina el vecindario local, que deriva el término de comunidad en los valores comunes que se producen por sus orígenes compartidos, fundamentados en las actividades, los comportamientos y los propósitos similares.

\section{Referencias}

Alcaldía Mayor de Bogotá. (2000). Decreto Distrital 619 de 2000. Alcaldía Mayor de Bogotá.

Díaz, L. (2013). La ilusión de la participación comunitaria de la doctora Noriko Hataya. Revista derecho y realidad, 21, 157-188. https://revistas.uptc.edu.co/index.php/ derecho realidad/article/view/4837/3930

Gutiérrez, L. R. (2009). Ciudad informal. Ediciones Uniandes.

Gómez, N. (2014). Partir de lo que somos. Ciudad Bolívar, tierra, agua y lucha. Alcaldía Mayor de Bogotá.

Hernández García, J. (2005). Participación y hábitat: ¿sueño posible o relación no deseada? Revista INVI, 20(55), 48-81. https://revistainvi.uchile.cl/index.php/INVI/ article/view/62163/66341

Jolly, J. F. (2016). A propósito de "cuadrinomio imperfecto": desarrollo humano, políticas públicas, planeación y territorio. En Desarrollo. Prácticas y narrativas emergentes en América Latina (pp. 85-121). CLACSO-
Instituto de estudio sociales y culturales, Pontificia Universidad Javeriana. https://bit.ly/3qY8tER

Jacobs, J. (2011). Muerte y vida de las grandes ciudades. Capitán Swing.

Lefebvre, H. (2013). La producción del espacio. Capitán Swing.

Morin, E. (2009). Introducción al pensamiento complejo. Editorial Gedisa.

Reyes-Guarnizo A. B. (2020). Comprensión del territorio para la construcción de apropiación e identidad en el municipio de Soacha. Revista de Arquitectura (Bogotá), 22(1), 44-57.

https://doi.org/10.14718/RevArq.2020.2651

Pedrazzani, C. (2016). Urbanizaciones populares: lógicas y condiciones de acceso de los sectores populares al espacio urbano en la ciudad. En Ciudades populares en disputas ¿Acceso al suelo urbano para todos? (pp. 365-386). ABYA-YALA - Universidad Federal de Rio De Janeiro - CLACSO. Ciudades populares_en_disputa.pdf (clacso.edu.ar)
Salingaros, N. (2004). Connecting the fractal city. Revista Planum, 8, 1-27. http://www.planum.net/connecting-thefractal-city

Secretaría Distrital de Hábitat. (2015). Evaluación política pública del programa vivienda y hábitat humanos.

Tavares-Martínez R. A., y Fitch-Osuna J. M. (2019). Planificación comunitaria en barrios socialmente vulnerables: identificación de los actores sociales en una comunidad. Revista de Arquitectura (Bogotá), 21(2), 22-32. https://doi.org/10.14718/RevArq.2019.21.2.2258

Torres, C., Rincón, J. y Vargas, J. (2009). Pobreza urbana y mejoramiento integral de barrios en Bogotá. Universidad Nacional de Colombia.

Zibechi, R. (2007). Autonomías y emancipaciones. América Latina en movimiento. Universidad Nacional Mayor de San Marcos. 

(1) Portada: Las bovedadas de Bramante.

Fotografía: Luis Alberto Martínez Camacho (2021) CC BY-NC

\section{(ब) (1) (\$)}

(A) Orientación editorial

\section{Enfoque y alcance}

La Revista de Arquitectura (Bogotá) ( (ISSN 1657-0308 Impresa y E-ISSN 2357-626X en línea) es una publicación científica seriada de acceso abierto, arbitrada mediante revisión por pares (doble ciego) e indexada, en donde se publican resultados de investigación originales e inéditos.

Está dirigida a la comunidad académica y profesional de las áreas afines a la disciplina. Es editada por la Facultad de Diseño y el Centro de Investigaciones (CIFAR) de la Universidad Católica de Colombia en Bogotá (Colombia).

La principal área científica a la que se adscribe la Revista de Arquitectura (Bogotá) según la OCDE es:

Gran área: 6. Humanidades

Área: 6.D. Arte

Disciplina: 6D07. Arquitectura y Urbanismo

También se publican artículos de las disciplinas como 2A02, Ingeniería arquitectónica; 5C03, Estudios urbanos (planificación y desarrollo); 6D07, Diseño.

Los objetivos de la Revista de Arquitectura (Bogotá) son:

- Promover la divulgación y difusión del conocimiento generado a nivel local, nacional e internacional

- Conformar un espacio para la construcción de comunidades académicas y la discusión en torno a las secciones definidas.

- Fomentar la diversidad institucional y geográfica de los autores que participan en la publicación.

- Potenciar la discusión de experiencias e intercambios científicos entre investigadores y profesionales.

- Contribuir a la visión integral de la arquitectura, por medio de la concurrencia y articulación de las secciones mediante la publicación de artículos de calidad.

- Publicar artículos originales e inéditos que han pasado por revisión de pares, para asegurar que se cumplen las normas éticas, de calidad, validez científica, editorial e investigativa.

- Fomentar la divulgación de las investigaciones y actividades desarrolladas en la Universidad Católica de Colombia.
Palabras clave de la Revista de Arquitectura (Bogotá): arquitectura, diseño, educación arquitectónica, proyecto y construcción, urbanismo.

Idiomas de publicación: español, inglés, portugués y francés. Título abreviado: Rev. Arquit.

Titulo corto: RevArq

\section{Políticas de sección}

La revista se estructura en tres secciones correspondientes a las líneas de investigación activas y aprobadas por la institución, y dos complementarias, que presentan dinámicas propias de la Facultad de Diseño y las publicaciones relacionadas con la disciplina.

Cultura y espacio urbano. En esta sección se publican los artículos que se refieren a fenómenos sociales en relación con el espacio urbano, atendiendo aspectos de la historia, el patrimonio cultural y físico, y la estructura formal de las ciudades y el territorio.

Proyecto arquitectónico y urbano. En esta sección se presentan artículos sobre el concepto de proyecto, entendido como elemento que define y orienta las condiciones proyectuales que devienen en los hechos arquitectónicos o urbanos, y la forma como estos se convierten en un proceso de investigación y nuevo de conocimiento. También se presentan proyectos que sean resultados de investigación, los cuales se validan por medio de la ejecución y transformación en obra construida del proceso investigativo. También se contempla la publicación de investigaciones relacionadas con la pedagogía y didáctica de la arquitectura, el urbanismo y el diseño.

Tecnología, medioambiente y sostenibilidad. En esta sección se presentan artículos acerca de sistemas estructurales, materiales y procesos constructivos, medioambiente y gestión, relacionados con los entornos social-cultural, ecológico y económico.

Desde la Facultad. En esta sección se publican artículos generados en la Facultad de Diseño, relacionados con las actividades de docencia, extensión, formación en investigación o internacionalización, las cuales son reflejo de la dinámica y de las actividades realizadas por docentes, estudiantes y egresados; esta sección no puede superar el $20 \%$ del contenido.

Textos. En esta sección se publican reseñas, traducciones y memorias de eventos relacionados con las publicaciones en Arquitectura y Urbanismo.
A Frecuencia de publicación

Desde 1999 y hasta el 2015, la Revista de Arquitectura (Bogotá) publicó un volumen al año, a partir del 2016 se publicarán dos números por año en periodo anticipado, enero-junio y julio-diciembre, pero también maneja la publicación anticipada en línea de los artículos aceptados (versión Post-print del autor).

La Revista de Arquitectura (Bogotá) se divulga mediante versiones digitales (PDF, HTML, EPUB, XML) e impresascon un tiraje de 700 ejemplares, los tiempos de producción de estas versiones dependerán de los cronogramas establecidos por la editorial.

Los tiempos de recepción-revisión-aceptación pueden tardar entre seis y doce meses dependiendo del flujo editorial de cada sección y del proceso de revisión y edición adelantado.

Con el usuario y contraseña asignados, los autores pueden ingresar a la plataforma de gestión editorial y verificar el estado de revisión, edición o publicación del artículo.
A Canje

La Revista de Arquitectura (Bogotá) está interesada en establecer canje con publicaciones académicas, profesionales o científicas del área de Arquitectura y Urbanismo, como medio de reconocimiento y discusión de la producción científica en el campo de acción de la publicación.

Mecanismo

Para establecer canje por favor descargar, diligenciar y enviar el formato: RevArq FP20 Canjes

Universidad Católica de Colombia (2021,
junio-diciembre). Revista de
Arquitectura (Bogotá), 23(2),
I-132. Doi: 10.14718
ISSN: I657-0308
E-ISSN: 2357-626X
Especificaciones:
Formato: $34 \times 24 \mathrm{~cm}$
Papel: Mate II5 g
Tintas: Negro y policromía

A Contacto

Dirección postal:

Avenida Caracas N ${ }^{0} \cdot 46-72$ Universidad Católica de Colombia Bogotá D. C., Colombia Código postal: 111311

Facultad de Diseño Centro de Investigaciones (CIFAR) Sede El Claustro. Bloque "L", 4 piso Diag. 46A N ${ }^{0 .} 15 b-10$ Editor, Arq. César Eligio-Triana

Teléfonos:

+57 (1) $3277300-3277333$

Ext. $3109 ; 3112$ o 5146
Fax: +57 (1) 2858895

Correo electrónico:

revistadearquitectura@ucatolica.edu.co cifar@ucatolica.edu.co

Página WEB:

www.ucatolica.edu.co

Vínculo Revistas científicas

http://publicaciones.ucatolica.edu.co revistas-cientificas

https://revistadearquitectura.ucatolica.edu.co/ 
